\title{
DSC and histological analysis of decellularized porcine biograft
}

\author{
Gábor Fazekas ${ }^{1}$. Gábor Jancsó ${ }^{2}$. Dénes Lőrinczy ${ }^{3}$
}

Received: 15 March 2020 / Accepted: 6 July 2020 / Published online: 22 July 2020

(c) The Author(s) 2020

\begin{abstract}
Different types of biological grafts are useful for the replacement of infected prostheses in vascular surgery. In cases, when autologous grafts or homografts are not available, xenografts can be an alternative choice. To reduce immunogenicity, decellularization of the xenogeneic graft is necessary. Our goal was to determine the long-lasting stability of our decellularized porcine vascular grafts, in the mirror of differential scanning calorimetry (DSC) and routine histological examination. In the first experiment, light and electron microscopic confirmation of adequate decellularization of our used protocol was assessed. In the second series, DSC measurements were performed both on native and on treated samples; thereafter, histological evaluation of the analyzed samples was performed. Light and electron microscopy evaluation showed complete removal of cells and preserved connective tissue fiber structure after decellularization in the first series. In the second part of our investigation, DSC measurements demonstrated reversible change in the structure of elastic fibers and irreversible change in the structure of collagen fiber structure supported by histological findings. Our examination strengthens the earlier observations that decellularized biological grafts can tend to late aneurysmatic degeneration, due to their weakened fiber structure, besides the known immunological circumstances.
\end{abstract}

Keywords Decellularization $\cdot$ Aorta $\cdot$ Biological graft $\cdot$ Calorimetry

\section{Introduction}

Currently, bypass surgery is still a frequent revascularization method in vascular surgery. The application of autologous graft remained the gold standard in lower-extremity reconstruction; however, in aortoiliac position, prosthetic grafts, particularly Dacron prostheses are the most commonly utilized synthetic vessels. Long-lasting stability, easy handling and unlimited availability are advantageous, but in case of graft infection, treatment and replacement are considered the most difficult challenges in vascular surgery, including high morbidity and mortality rate. Limb salvage and survival of the patient can be effectively achieved by graft replacement. Among other options (autologous deep vein, homograft,

Dénes Lőrinczy

denes.lorinczy@aok.pte.hu

1 Departments of Vascular Surgery, Medical School, University of Pécs, Pécs, Hungary

2 Surgical Research and Techniques, Medical School, University of Pécs, Pécs, Hungary

3 Department of Biophysics, Medical School, University of Pécs, Pécs Szigeti Str. 12, 7624 Pécs, Hungary impregnated graft), the usage of biological xenogeneic graft can be an alternative solution.

After doubtful early attempts [1,2], the attention has pointed toward the development of biological xenografts with adequate biomechanical properties, high resistance against infections and unlimited availability [3-5]. By decellularization of the vessel, the immunogenicity can be reduced, preventing the implanted graft from deterioration [3-10]. Several efficient decellularization methods were previously published testing the mechanical properties of treated vessels with different methodologies [3, 4, 6-10]; however, mechanical stability of cell-free grafts based on differential scanning calorimetry (DSC) in consideration of histological evaluation was first assessed in our study.

Our aim was to analyze the effects of decellularization on the connective tissue fiber structure of the treated porcine aortic wall with calorimetric and histological examinations, thus concluding on the long-term outcome after implantation. 


\section{Materials and methods}

\section{Surgical preparation}

The present study conforms to the Guide for the Care and Use of Laboratory Animals published by the US National Institute of Health (NIH Publication No. 85-23, revised 1996) and was approved by the local institutional Committee on Animal Research, University of Pécs (BA02/2000-29/2001).

Infrarenal aortic segments were freshly excised under sterile surgical conditions from euthanized Yorkshire pigs (mass from 22 to $27 \mathrm{~kg}$ ) of other ongoing experiments, declared free of clinically evident diseases. Following separation of the adhesive tissue, a macroscopic examination was performed to exclude any pathology, and longitudinal aortic segments (about $10 \mathrm{~mm}$ in length and $6 \mathrm{~mm}$ in width) were next washed in sterile phosphate-buffered saline (PBS) to remove residual traces of blood.

\section{Decellularization protocol}

Aortic segments were decellularized through continuous shaking in $1 \%$ sodium dodecyl sulfate (SDS; Sigma-Aldrich
Chemie GmbH, Steinheim, Germany), 0.05\% sodium azide $\left(\mathrm{NaN}_{3}\right.$; Alfa Aesar GmbH \& $\mathrm{Co}$, Karlsruhe, Germany) and phosphate-buffered saline (PBS; Sigma-Aldrich Chemie $\mathrm{GmbH}$, Steinheim, Germany), at room temperature, for $48 \mathrm{~h}$. The solution was exchanged in every $6 \mathrm{~h}$. At the end of the decellularization protocol, the aortic segments were washed using PBS for $12 \mathrm{~h}$ to effectively remove residual detergents and cell debris, then stored in Medium 199 with Earle's salts (Biowest, Nuaillé, France) and maintained at $4{ }^{\circ} \mathrm{C}$, until measurements $[9,10]$.

\section{Light microscopy evaluation}

Samples were fixed for $24 \mathrm{~h}$ in $10 \%$ neutral buffered formalin, in support of routine histological examination. Longitudinal and cross-sectional tissue blocks were embedded using paraffin, and 2-4- $\mu \mathrm{m}$-thick sections were sliced. Sections were stained applying hematoxylin-eosin (HE) staining to evaluate the effectiveness of decellularization. Besides this, Masson trichrome (MT) and orcein (O) histochemistry was used to examine the changes in the structure of the connective tissue fibers, using protocol recommended by the manufacturers. HE-, MT- and orcein-stained histological sections of decellularized and native samples before and after DSC
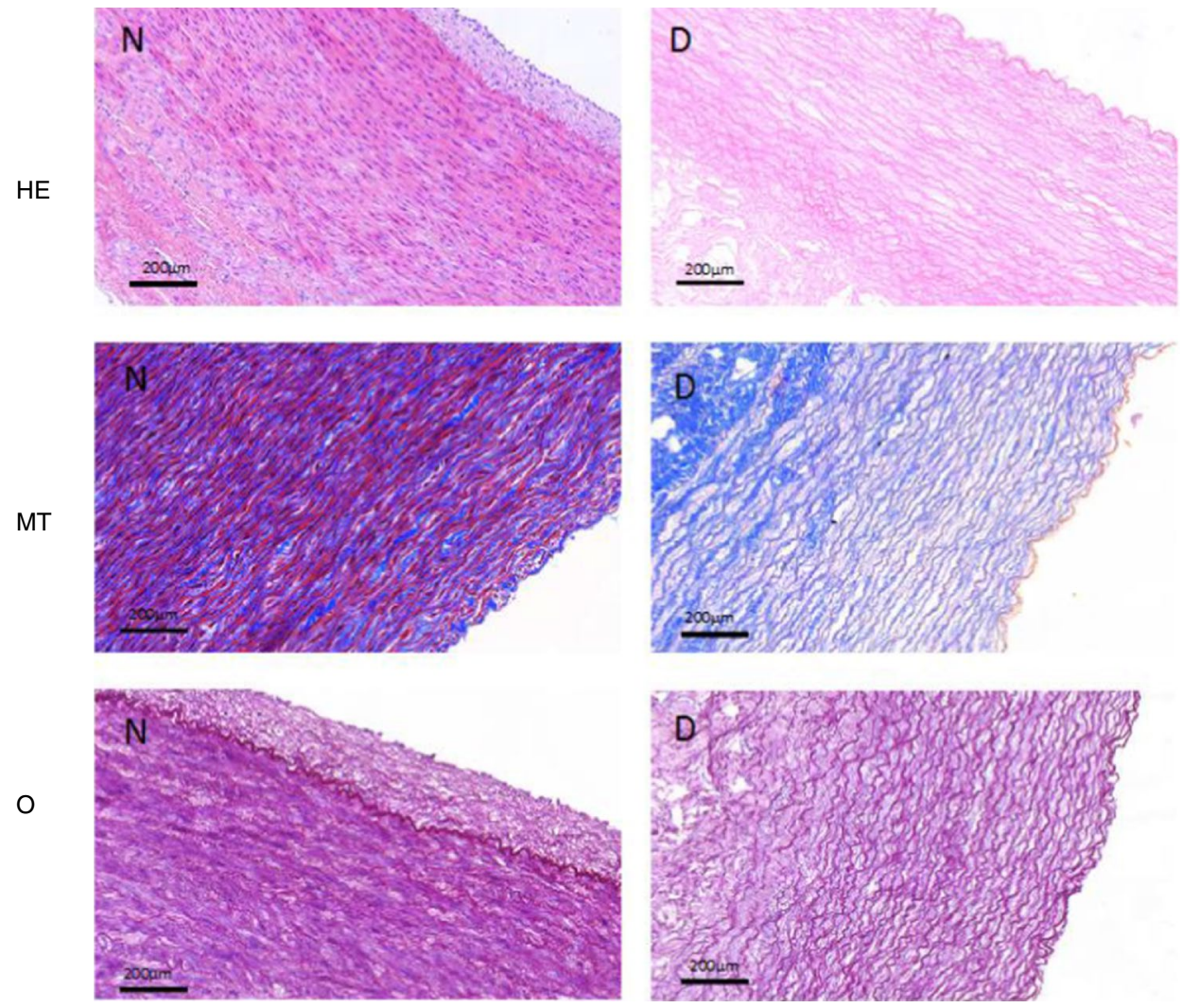

Fig. 1 Hematoxylin-eosin (HE), Masson trichrome (MT) and orcein (O) staining of native (N) and decellularized (D) aortic wall 
were compared and analyzed using Pannoramic Viewer software (3DHistech Ltd.) and were evaluated by two independent pathologists. Six samples $(n=6)$ were assessed in each group.

\section{Transmission electron microscopy (TEM) assessment}

Samples were prepared for TEM examination by fixation in $2 \%$ formaldehyde- and $2.5 \%$ glutaraldehyde-containing solution, for $12 \mathrm{~h}$, at $4{ }^{\circ} \mathrm{C}$. Following fixation, 50-60-nmthick sections were cut, and examination was performed using a JEOL JEM-1200EX II transmission electron microscope, at $80 \mathrm{kV}$.

\section{DSC measurements}

The thermal denaturation of the samples was investigated with a SETARAM Micro DSC-II calorimeter. Each analysis
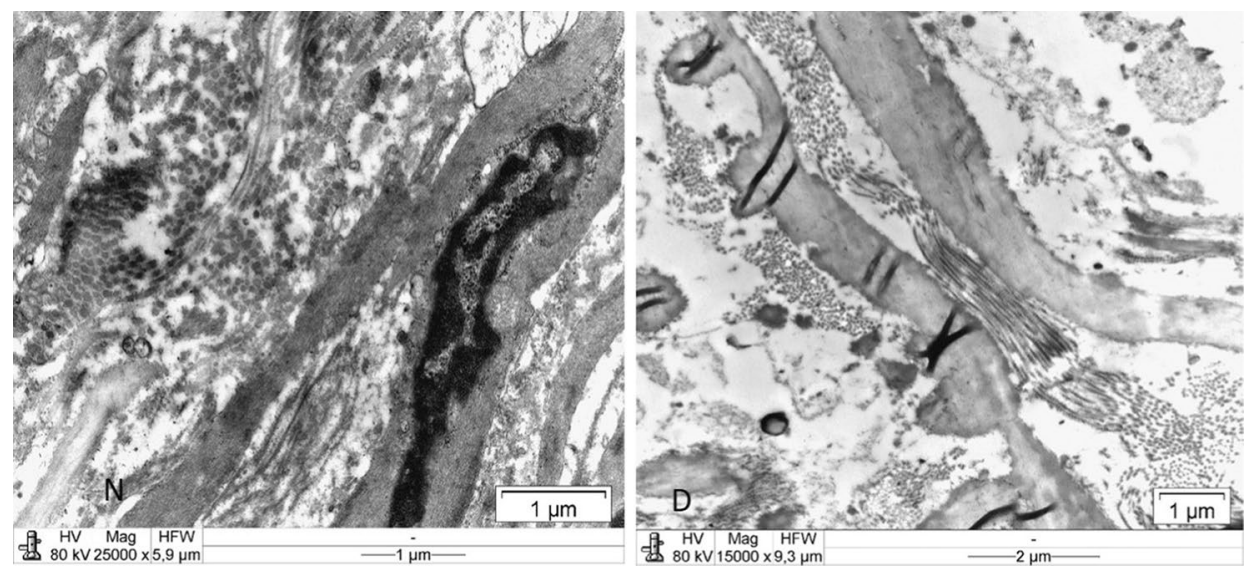

Fig. 2 TEM images of native (N) and decellularized (D) aortic walls

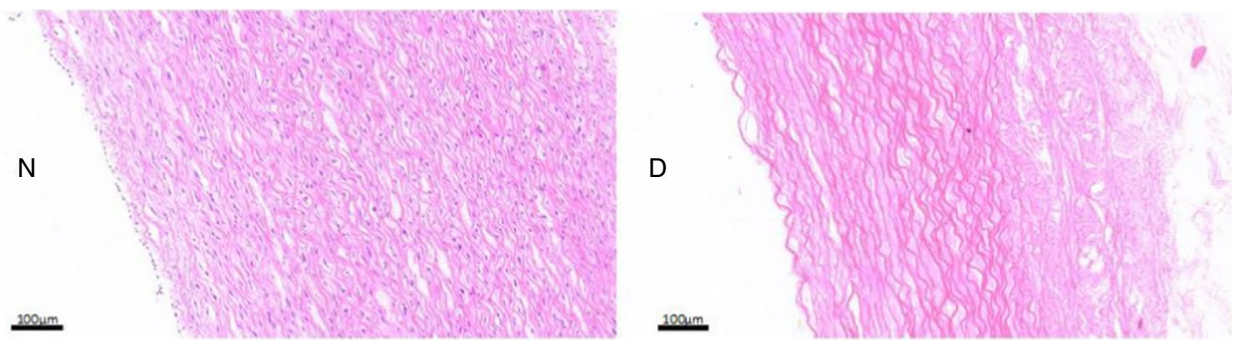

Fig. 3 HE staining of native (N) and decellularized (D) aortic walls after DSC analysis
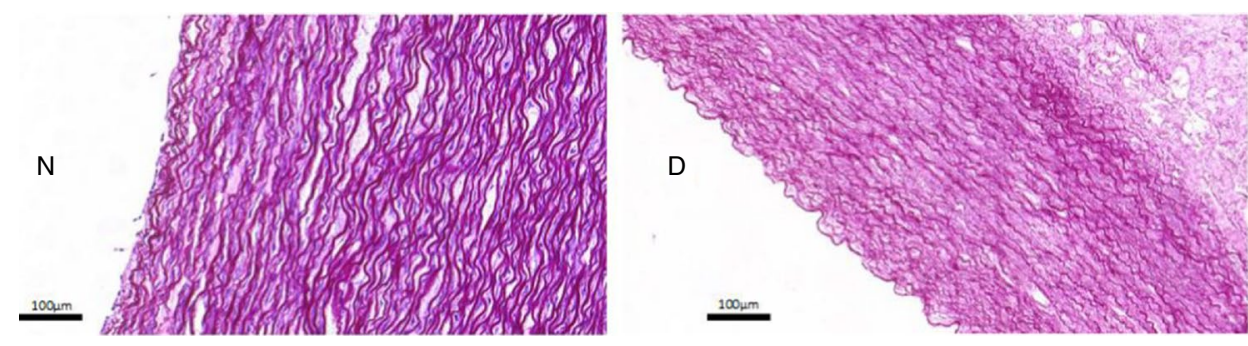

Fig. 4 Orcein staining of native (N) and decellularized (D) aortic walls after DSC analysis 

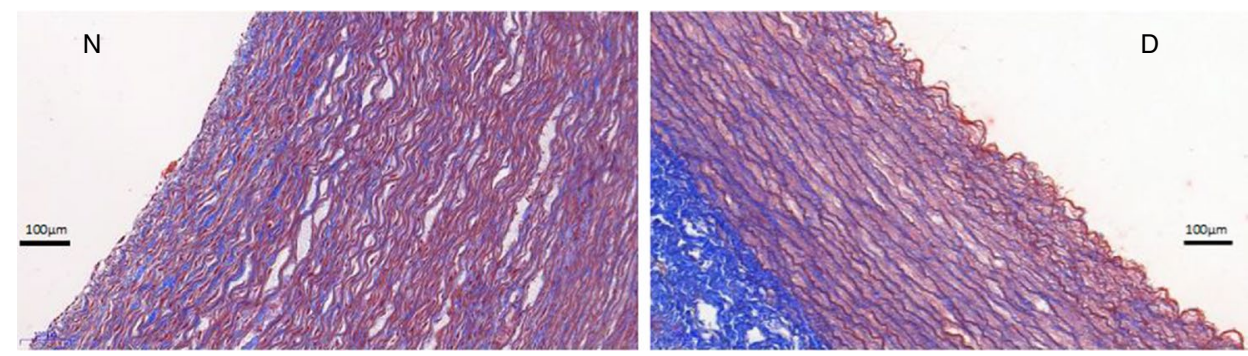

Fig. 5 MT staining of native (N) and decellularized (D) aortic walls after DSC analysis

was performed within the range of 0 and $100{ }^{\circ} \mathrm{C}$ with a heating rate of $0.3 \mathrm{~K} \mathrm{~min}^{-1}$. Conventional Hastelloy batch vessels $\left(V_{\max }=1 \mathrm{~mL}\right)$ were applied for the experiment with an average sample mass of $\sim 150 \mathrm{mg}$ (range 110-200 mg). Normal saline solution was used as a reference. The reference and sample vessels were equilibrated with a precision of $\pm 0.1 \mathrm{mg}$, so heat capacity correction between the sample and reference was not needed. Routine baseline correction is performed by a second scan of the denatured samples. In recent experiments, our samples showed the presence of partially reversible compounds, so we used the appropriate part of the Origin 6.0 software to smooth the experimental curves and correct the baseline. The melting temperature of the samples $\left(T_{\mathrm{m}}\right)$ was defined as the peak of the heat transition curves (at this point the $50 \%$ of sample turns from native into denatured state). The calorimetric enthalpy change $\left(\Delta H_{\text {cal }}\right)$ was calculated from the area under the heat absorption curve with the SETARAM two-point setting software. The sample size in grams was used to normalize the $\Delta H_{\text {cal }}$ values (in $\mathrm{J} \mathrm{g}^{-1}$ unit).

\section{Results and discussion}

Nowadays, the utilization of biological xenografts (graft originates from another species) shows an increasing number, as a result of the growing demands in vascular surgery, decisively in the treatment of septic vascular prostheses [11-14]. However, frequent, late aneurysm formation due to their degeneration is the most unfavorable consequence of their use. A well-known reason behind it is the immunemediated graft rejection $[6,10,15]$. Several different types of mechanical tests were previously performed; nevertheless, none of them could provide information on, whether there was any association between late graft degeneration and decellularization treatment. DSC analysis can reveal structural alteration of macromolecules, before the defect of tissues becomes evident [16]. Up to the present day, we found just a few publications in the literature used DSC analysis
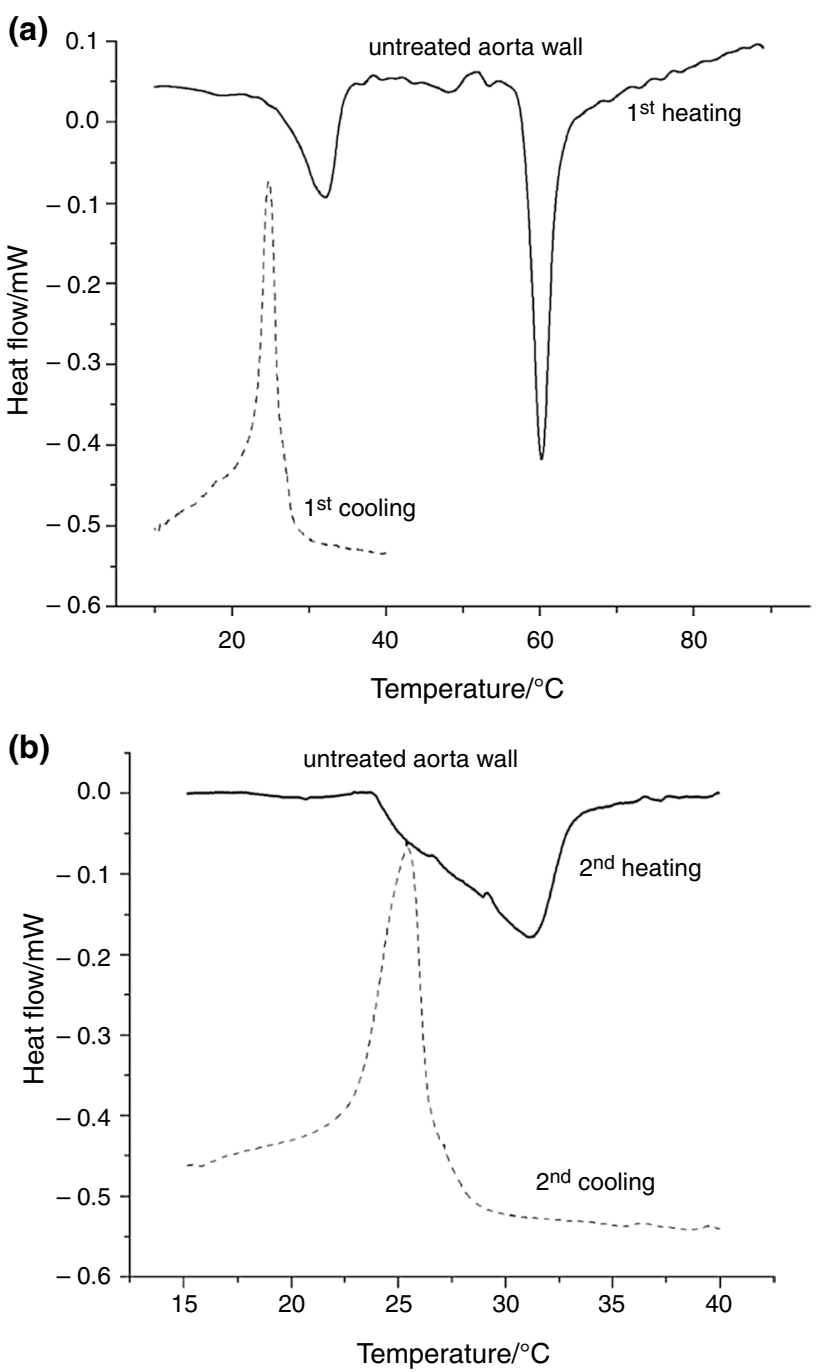

Fig. 6 a The denaturation and renaturation heat flows of untreated aorta to illustrate the main thermal processes in the first heating-cooling cycle (after smoothing and baseline correction using Origin 6). b The denaturation and renaturation heat flows of untreated aorta in the second heating-cooling cycle focusing on the low-temperature range (after smoothing and baseline correction using Origin 6) 
Table 1 The average characteristic thermal parameters of the denaturation processes: $\Delta T /{ }^{\circ} \mathrm{C}$ stands for the temperature range of transition, $T_{\mathrm{m}} /{ }^{\circ} \mathrm{C}$ is the denaturation temperature at the maximum of the given heat flow and $\Delta H / \mathrm{J} \mathrm{g}^{-1}$ is the calorimetric enthalpy normalized on the wet mass of the sample

\begin{tabular}{|c|c|c|c|c|c|c|c|}
\hline \multicolumn{8}{|l|}{ Native samples } \\
\hline \multicolumn{4}{|c|}{ Low-temperature range } & \multicolumn{4}{|c|}{ High-temperature range } \\
\hline$n=6$ & $\Delta T /{ }^{\circ} \mathrm{C}$ & $T_{\mathrm{m}} /{ }^{\circ} \mathrm{C}$ & $\Delta H / \mathrm{J} \mathrm{g}^{-1}$ & $\Delta T /{ }^{\circ} \mathrm{C}$ & $T_{\mathrm{m} 1} /{ }^{\circ} \mathrm{C}$ & $T_{\mathrm{m} 2} /{ }^{\circ} \mathrm{C}$ & $\Delta \mathrm{H} / \mathrm{J} \mathrm{g}^{-1}$ \\
\hline First heating & 15 & 30.8 & 5.4 & 24 & 53.4 & 59.6 & 25 \\
\hline Cooling & 16 & 23.5 & -1.3 & & & & \\
\hline Second heating & 16 & 29.2 & 7.1 & & & & \\
\hline Cooling & 16 & 22.5 & -1.3 & & & & \\
\hline
\end{tabular}

Treated samples

Low-temperature range

\begin{tabular}{|c|c|c|c|c|c|c|c|c|c|c|}
\hline$n=8$ & $\Delta T /{ }^{\circ} \mathrm{C}$ & $T_{\mathrm{m} 1} /{ }^{\circ} \mathrm{C}$ & $\Delta H / \mathrm{J} \mathrm{g}^{-1}$ & $\Delta T /{ }^{\circ} \mathrm{C}$ & $T_{\mathrm{m} 2} /{ }^{\circ} \mathrm{C}$ & $\Delta H / \mathrm{J} \mathrm{g}^{-1}$ & $\Delta T /{ }^{\circ} \mathrm{C}$ & $T_{\mathrm{m} 1} /{ }^{\circ} \mathrm{C}$ & $T_{\mathrm{m} 2} /{ }^{\circ} \mathrm{C}$ & $\Delta H / \mathrm{J} \mathrm{g}^{-1}$ \\
\hline First heating & 16 & 7.4 & 2.95 & 16 & 37.8 & 2.14 & 33 & 47 & 56 & 6.8 \\
\hline Cooling & & & & 14 & 21.5 & -1.18 & & & & \\
\hline Second heating & 13 & 9.1 & 1.68 & 19 & 31.2 & 1.93 & & & & \\
\hline Cooling & & & & 15 & 22.5 & -2.8 & & & & \\
\hline
\end{tabular}

for characterization of decellularized aortic wall [17, 18]. We have planned and performed histological evaluation and DSC analysis of the decellularized porcine aortic wall, to assess the structural changes following treatment, which can affect the long-term mechanical stability.

\section{Light microscopy evaluation of native and decellularized aortic wall}

In the first series, decellularized samples were compared with native aortic sections as controls, to confirm the effectiveness of decellularization protocol. Histological findings with HE staining demonstrated complete cell removal in treated samples, and there were not visible, blue-stained cell nuclei on the slices of decellularized aortic wall. MT and orcein histochemistry confirmed preserved structure of connective tissue fibers (collagen and elastic fibers) after decellularization. Compared with the untreated aortic wall, on cross-sectional slices of decellularized aorta only the two layers, tunica media and adventitia, were identifiable, and decreased wall thickness was noticeable in case of each treated sample. These findings were proved consistently uniform throughout all investigated samples (Fig. 1).

\section{Transmission electron microscopy assessment}

TEM images confirmed the absence of cells and cell nuclei among the preserved, regular-structured collagen fibers (Fig. 2).

\section{Histological analysis after thermal denaturation}

In the second series, we compared the native, untreated and the decellularized aortic sections before and after DSC measurements. The routine, HE-stained sections showed minor alteration in the structure of connective tissue fibers after DSC analysis, and this change was more significant in the surface near the luminal, where some fragmentation of fibers was detectable (Fig. 3).

Collagen and elastic fibers were stained selectively with specific immunohistochemistry to better illustrate the structural changes of the different types of fibers. Orcein staining showed no detectable alteration in the elastic fiber structure after DSC measurement, the run of the fibers is regular, and there was no significant difference compared with the native aorta (Fig. 4).

In case of MT staining, which is specific for collagen, there are some irregular, more undulatory, slightly fragmented collagen fibers, especially near the luminal surface, which suggests mild damage in their structure following decellularization treatment (Fig. 5).

\section{Thermal denaturation measurements}

Aortic segments underwent two heating-cooling cycles. In the case of the first step, we have checked the reversibility of thermal transitions under cooling, and the second one is generally used to perform instrument baseline correction. The samples were denoted as untreated and decellularized. Figure 6a shows a typical first heating-cooling cycle of untreated aorta wall. 

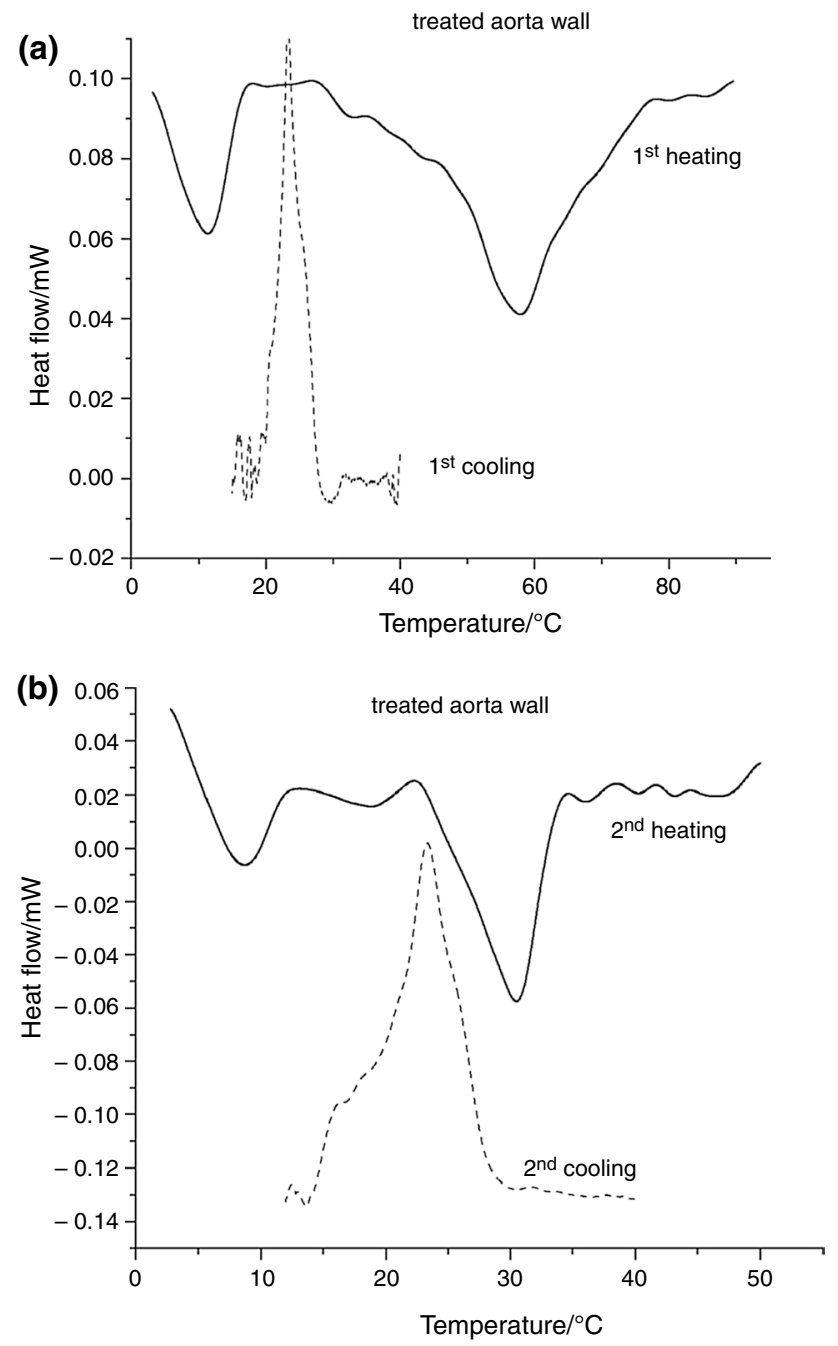

Fig. 7 a The characteristic DSC scan of treated aorta wall with an unidentified elastic compound melting $\left(\sim 10^{\circ} \mathrm{C}\right)$ and a less cooperative main endotherm $\left(\sim 60^{\circ} \mathrm{C}\right)$. b The characteristic thermal transitions of treated aorta wall. The unidentified elastic compound melting $\left(\sim 10^{\circ} \mathrm{C}\right)$ reappeared after the first denaturation. The elastin contribution became more pronounced, and during cooling, the elastic domains make a complex exothermic peak nearly in the same temperature range, as in case of the first cooling phase

During heating, two major denaturation processes are going on: Very probably around $30^{\circ} \mathrm{C}$ is the thermal transition of elastin [19] and $\sim 60{ }^{\circ} \mathrm{C}$ the collagen denaturation [20-24]. Some small pretransition can be seen $\sim 20$ and 48 as well as at $54{ }^{\circ} \mathrm{C}$. These two later peaks (which give only small enthalpy contribution) should have a myosin and actin origin on the basis of measurements performed on muscle protein solutions and skeletal muscle fibers [25-31]. In the literature, we have not found similar experiments performed on smooth muscles. The cooling process showed a near $100 \%$ renaturation in enthalpy of the denaturation peak at $\sim 30{ }^{\circ} \mathrm{C}$ as an exothermic peak of $25^{\circ} \mathrm{C}$. The main denaturation transition $\left(\sim 60^{\circ} \mathrm{C}\right)$ disappeared during cooling, indicating that the change in collagen structure during denaturation is irreversible (Table 1).

The second heating-cooling cycle exhibited surprising result (Fig. 6b). The low-temperature endotherm and exotherm remained in the same temperature range and $T_{\mathrm{m}}$ with practically unchanged calorimetric enthalpies, while the higher transitions disappeared.

During the first heating-cooling cycle of the treated aorta wall, a low endotherm appeared around $10{ }^{\circ} \mathrm{C}$, which was detectable many times in case of cross-striated muscle fibers (unpublished data), and we could not attach it to any structural element (Fig. 7a).

The elastin compound enthalpy contribution $\sim 30{ }^{\circ} \mathrm{C}$ decreased, and the main transition became wider. The socalled $T_{1 / 2}$ half width (the temperature range where the heat flow is half of its maximum) extremely increased, informing about the structural loosening compared with the untreated samples, as a consequence of removing most of the muscle proteins during the treatment. It means that the strength of cooperativity depends on the protein collagen matrix interaction. It can be the sign of the decreased elastic capability of aorta wall. In case of the cooling phase, only one dominating sharp exothermic peak was detected, referring basically to the elastin refolding.

Under the second heating-cooling cycle of treated sample (Fig. 7b), during heating the low-temperature melting position has shown about $2{ }^{\circ} \mathrm{C}$ shift to lower value, and the elastin melting became higher in calorimetric enthalpy. The cooling cycle exhibited a "fusion" exotherm of elastic compounds during refolding.

\section{Conclusions}

Earlier attempts demonstrated adequate biomechanical properties and suture retention of cell-free vascular grafts $[3,10]$. However, these investigations did not provide eligible information about the microstructural changes in the connective tissue fibers that may influence the mechanical stability and long-term behavior of these decellularized vessels. For this purpose, DSC analysis was performed.

Our results showed that after decellularization of the aortic tissue, minor structural changes develop in the scaffold, which can decrease the mechanical stability, and consequently the long-term durability of the treated xenograft. Decellularization process causes mild connective tissue fiber damage: irreversible structural change in collagen fibers and reversible alteration in the structure of elastin fibers, which leads to weakened scaffold strength and reduced elasticity. These factors, together with the decreased vessel wall thickness, predispose for the development of late degenerative complications and consecutive aneurysm formation. 
This work demonstrated that for the above-mentioned late consequences of cell-free grafts' utilization not only the well-known graft versus host immune reaction, but also the decellularization treatment of the vessel is responsible. Therefore, in cases, when biological xenografts' application is necessary for human application, postoperative close follow-up is mandatory.

For the future, DSC examination can be used to investigate the effects of different types of decellularization methods on the vessels' connective tissue fiber structure.

Acknowledgements Open access funding provided by University of Pécs. This work was supported by CO-272 (OTKA) Grant (D.L.).

Open Access This article is licensed under a Creative Commons Attribution 4.0 International License, which permits use, sharing, adaptation, distribution and reproduction in any medium or format, as long as you give appropriate credit to the original author(s) and the source, provide a link to the Creative Commons licence, and indicate if changes were made. The images or other third party material in this article are included in the article's Creative Commons licence, unless indicated otherwise in a credit line to the material. If material is not included in the article's Creative Commons licence and your intended use is not permitted by statutory regulation or exceeds the permitted use, you will need to obtain permission directly from the copyright holder. To view a copy of this licence, visit http://creativecommons.org/licenses/by/4.0/.

\section{References}

1. Nemes A, Acsády G, Fraefel W, Lichti H, Monos E, Oertli R, Somogyi E, Sótonyi P. Application of a vascular graft material (Solcograft-P) in experimental surgery. Biomaterials. 1985;6(5):303-11.

2. Schröder A, Imig H, Peiper U, Neidel J, Petereit A. Results of a bovine collagen vascular graft (Solcograft-P) in infra-inguinal positions. Eur J Vasc Surg. 1988;2(5):315-21.

3. Fitzpatrick JC, Clark PM, Capaldi FM. Effect of decellularization protocol on the mechanical behavior of porcine descending aorta. Int J Biomater; 2010. https://doi.org/10.1155/2010/620503.

4. Xiong Y, Chan WY, Chua AW, Feng J, Gopal P, Ong YS, Song C. Decellularized porcine saphenous artery for small-diameter tissue-engineered conduit graft. Artif Organs. 2013;37(6):74-87.

5. Töpel I, Uhl C, Ayx I, Steinbauer M. Xenografts in septic vascular surgery. Gefasschirurgie. 2016;21(Suppl2):55-8.

6. Gilbert TW, Sellaro TL, Badylak SF. Decellularization of tissues and organs. Biomaterials. 2006;27(19):3675-83.

7. Crapo PM, Gilbert TW, Badylak SF. An overview of tissue and whole organ decellularization processes. Biomaterials. 2011;32(12):3233-43.

8. Conklin BS, Richter ER, Kreutziger KL, Zhong DS, Chen C. Development and evaluation of a novel decellularized vascular xenograft. Med Eng Phys. 2002;24(3):173-83.

9. Weymann A, Radovits T, Schmack B, Korkmaz S, Li S, Chaimow N, Pätzold I, Becher PM, Hartyánszky I, Soós P, Merkely G, Németh BT, Istók R, Veres G, Merkely B, Terytze K, Karck M, Szabó G. Total aortic arch replacement: superior ventriculo-arterial coupling with decellularized allografts compared with conventional prostheses. PLoS ONE. 2014;9(7):e103588.

10. Fazekas G, Benkő L, Kasza G, Arató E, Sínay L, Jávor S, Nagy T, Hardi P, Kollár L, Jancsó G, Menyhei G. Histological and mechanical assessment of decellularized porcine biografts, and its biological evaluation following aortic implantation during mid-term follow-up. J Vasc Res. 2018;55:287-98.

11. McMillan WD, Leville CD, Hile CN. Bovine pericardial patch repair in infected fields. J Vasc Surg. 2012;55(6):1712-5.

12. Czerny M, von Allmen R, Opfermann P, Sodeck G, Dick F, Stellmes A, Makaloski V, Bühlmann R, Derungs U, Widmer MK, Carrel T, Schmidli J. Self-made pericardial tube graft: a new surgical concept for treatment of graft infections after thoracic and abdominal aortic procedures. Ann Thorac Surg. 2011;92(5):1657-62.

13. Dulbecco E, Camporrotondo M, Blanco G, Haberman D. In situ reconstruction with bovine pericardial tubular graft for aortic graft infection. Rev Bras Circ Cardiovasc. 2010;25(2):249-52.

14. Lutz B, Reeps C, Biro G, Knappich C, Zimmermann A, Eckstein $\mathrm{HH}$. Bovine pericardium as new technical option for in situ reconstruction of aortic graft infection. Ann Vasc Surg. 2016;41:118-26.

15. Colaco M, Atala A. The future of transplant biology and surgery. Interdiscip Med; 2014;15:206-18.

16. Mintál T, Patczai B, Wiegand N, Kereskai L, Váncsodi J, Lôrinczy D. The effect of deep-freezing on the structure of patellar and Achilles tendon allografts used for ACL reconstruction. J Therm Anal Calorim. 2017;127:1171-5.

17. Samouillan V, Delaunay F, Dandurand J, Merbahi N, Gardou JP, Yousfi M, Gandaglia A, Spina M, Lacabanne C. The use of thermal techniques for the characterization and selection of natural biomaterials. J Funct Biomater. 2011;2:230-48.

18. Samouillan V, Lamure A, Maurel E, Dandurand J, Lacabanne C, Ballarin F, Spina M. Characterisation of elastin and collagen in aortic bioprosthesis. Med Biol Eng Comput. 2000;38(2):226-31.

19. Christensen T, Hassouneh W, Trabbic-Carlson K, Chilkoti A. Predicting transition temperatures of elastin-like polypeptide fusion proteins. Biomacromol. 2013;14(5):1514-9.

20. Miles CA, Wardale RJ, Birch HL, Bailey AJ. Differential scanning calorimetric studies of superficial digital flexor tendon degeneration in the horse. Equine Vet J. 1994;26:255-61.

21. Willett TL, Labow RS, Avery NC, Lee JM. Increased proteolysis of collagen in an in vitro tensile overload tendon model. Ann Biomed Eng. 2007;35(11):1961-72.

22. Willett TL, Labow RS, Lee JM. Mechanical overload decreases the thermal stability of collagen in an in vitro tensile overload tendon model. J Orthop Res. 2008;26(12):1605-10.

23. Willett TL, Labow RS, Lee JM. Thermal stability of collagen in an in vitro tensile overload tendon model. J Bone Joint Soc Br. 2009;91:217-20.

24. Wiegand N, Vámhidy L, Lőrinczy D. Differential scanning calorimetric examination of ruptured lower limb tendons in human. J Therm Anal Calorim. 2010;101:487-92.

25. Lőrinczy D, Belágyi J. Effects of nucleotide on skeletal muscle myosin unfolding in myofibrils by DSC. Biochem Biophys Res Commun. 1995;217:592-8.

26. Belágyi J, Lőrinczy D. Internal motions in the catalytic domain of myosin heads in muscle fibres. Effects of ADP and ATP. Biochem Biophys Res Commun. 1996;219:936-40.

27. Lőrinczy D, Belágyi J. Comparative study of myosins in solutions and supramolecular complexes. Effect of nucleotides. Thermochim Acta. 1997;296:18-161.

28. Lőrinczy D, Könczöl F, Gaszner B, Belágyi J. Structural stability of actin as studied by DSC and EPR. Thermochim Acta. 1998;322:95-100.

29. Lőrinczy D, Belágyi J. Nucleotide binding induces global and local structural changes of myosin head in muscle fibres. Eur $\mathrm{J}$ Biochem. 2001;268:5970-6. 
30. Dergez T, Lőrinczy D, Könczöl F, Farkas N, Belagyi J. Differential scanning calorimetry study of glycerinated rabbit psoas muscle fibres in intermediate state of ATP hydrolysis. BMC Struct Biol. 2007;7:41-50.
31. Lőrinczy D, Vértes ZS, Könczöl F, Belagyi J. Thermal transitions of actin. J Therm Anal Calorim. 2009;95:713-9.

Publisher's Note Springer Nature remains neutral with regard to jurisdictional claims in published maps and institutional affiliations. 